University of Wollongong

Research Online

Australian Institute for Innovative Materials -

Papers

Australian Institute for Innovative Materials

$1-1-2018$

\title{
Future Energy Technology: Enabling New Science for a Sustainable Future
}

Francois Aguey-Zinsou

University of New South Wales, f.aguey@unsw.edu.au

Zaiping Guo

University of Wollongong, zguo@uow.edu.au

Yun Hau Ng

University of New South Wales, yh.ng@unsw.edu.au

Da-Wei Wang

University of New South Wales, da-wei.wang@unsw.edu.au

Follow this and additional works at: https://ro.uow.edu.au/aiimpapers

Part of the Engineering Commons, and the Physical Sciences and Mathematics Commons

Research Online is the open access institutional repository for the University of Wollongong. For further information contact the UOW Library: research-pubs@uow.edu.au 


\title{
Future Energy Technology: Enabling New Science for a Sustainable Future
}

\author{
Abstract \\ With the financial crisis hitting the world economy in 2008, the boom of gas shale and fracking in the US, \\ and the recent move toward outdated technologies in some parts of the world, tackling many of the \\ challenges facing humanity in the 21 st century has been relegated to second place. The supply of clean \\ energy is one of those challenges. The test facing us is how to sustain economic growth while dealing \\ with limited primary resources and minimizing environmental pollution. Energy is a fundamental necessity \\ for almost everything needed to sustain us, from food production to drug design and safe drinking water. \\ Our quality of life is reflected by the human development index, which strongly correlates with the \\ availability of energy

\section{Disciplines} \\ Engineering | Physical Sciences and Mathematics

\section{Publication Details} \\ Aguey-Zinsou, F., Guo, Z., Ng, Y. \& Wang, D. (2018). Future Energy Technology: Enabling New Science for a \\ Sustainable Future. ChemPlusChem, 83 (10),
}




\title{
firubich

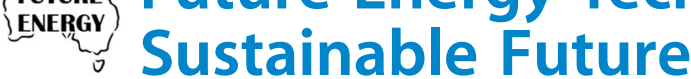

\author{
François Aguey-Zinsou, ${ }^{*[a]}$ Zaiping Guo, ${ }^{*[b]}$ Yun Hau Ng, ${ }^{*[a]}$ and Da-wei Wang ${ }^{*[a]}$
}

With the financial crisis hitting the world economy in 2008, the boom of gas shale and fracking in the US, and the recent move toward outdated technologies in some parts of the world, tackling many of the challenges facing humanity in the 21 st century has been relegated to second place. The supply of clean energy is one of those challenges. The test facing us is how to sustain economic growth while dealing with limited primary resources and minimizing environmental pollution Energy is a fundamental necessity for almost everything needed to sustain us, from food production to drug design and safe drinking water. Our quality of life is reflected by the human development index, which strongly correlates with the availability of energy (Figure 1). ${ }^{[1]}$

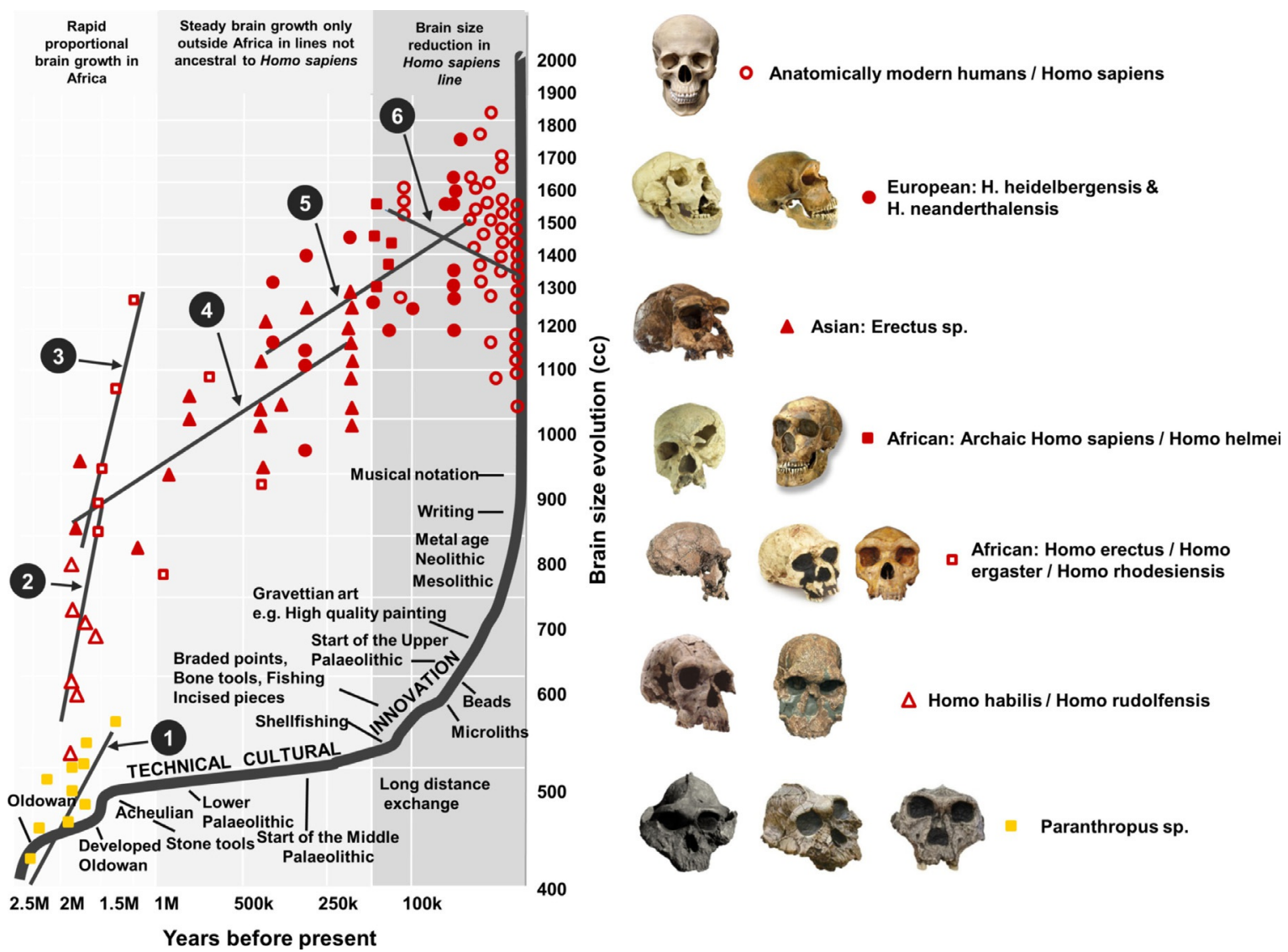

Figure 1. Since the early stages of human existence, access to energy has always been the vector for evolution. As we evolved to bipedalism and our brain size increased as a result of access to a richer diet of meat and seafood, we developed the ability to take control over our evolution at a much greater pace than possible through natural systems. This led to the industrial revolution. A paradigm shift is now required to decouple ourselves from natural fossil fuels cycles. Picture on the left was adapted with permission from Stephen Oppenheimer's book Out of Eden: The Peopling of the World, copyright 2004, Robinson Publishing Ltd.

[a] Prof. F. Aguey-Zinsou, Dr. Y. H. Ng, Dr. D.-w. Wang School of Chemical Engineering University of New South Wales Sydney, NSW 2033 (Australia) E-mail:f.aguey@unsw.edu.au yh.ng@unsw.edu.au da-wei.wang@unsw.edu.au [b] Prof. Z. Guo

Institute for Superconducting \& Electronic Materials

University of Wollongong

Wollongong, NSW 2500 (Australia)

E-mail:zguo@uow.edu.au

fữû, This article is part of a Special Issue on "Future Energy Technology". To view the complete issue, visit: https://doi.org/10.1002/cplu.v83.10. 
By 2050, the world population is predicted to reach 10 billion (7.6 billion in 2018) and energy consumption is due to double to support the growing economies of China and India. ${ }^{[2]}$ Optimistic predictions would argue that our planet could easily support 10 billion people, but it is difficult to see how established societal and economic models that have powered economic growth since the industrial revolution can possibly sustain similar rates of development throughout the 21st century unless a majority of the world's population is deprived of reasonable living standards. The consumption/depletion of many resources would typically follow a logarithmic curve, akin to Hubbert's prediction of the oil peak in the US; ${ }^{[3]}$ and it is likely that our current energy-based system would follow a similar trend because of no action. Many of us were born with energy readily available in our homes, and the current ubiquity of electronic goods does not help the general appreciation of the level of scientific and technological difficulties in supplying energy once fossil fuel resources are depleted. Ensuring energy security for future generations will require sustained research and scale-up efforts in materials science, biology and engineer- ing to solve the challenges associated with a shift to renewable energy sources.

The most obvious renewable energy source is the sun, and nature has developed efficient ways to build stable ecosystems based on solar outputs. This should serve as inspiration to finally complete our energy evolution. As people moved from the consumption of wood to coal and oil, the increasing energy content of these sources enabled us to extract more power to do work. The ultimate replacement of these sources would be to finally adopt hydrogen as an energy carrier and its direct production from the sun through water splitting would lead to sustainable energy systems. Hydrogen is a clean fuel with high energy density $\left(142 \mathrm{MJ} \mathrm{kg}^{-1}\right.$, almost three times that of liquid hydrocarbons, $\left.47 \mathrm{MJ} \mathrm{kg}^{-1}\right) \cdot{ }^{[4]}$ Its combustion, either direct or in a fuel cell, leads to water as the sole product. A major advantage of hydrogen over conventional fuels is the possibility of building decentralised energy systems like natural ecosystems that are self-supporting of life and maximising overall efficiency figures. Through the use of locally available renewable sources (e.g. biomass, wind or solar) hydrogen

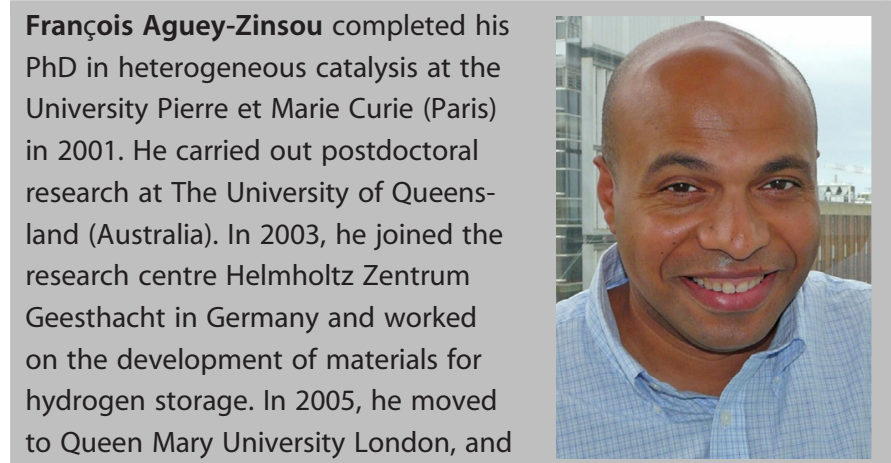
later onto University College London. In 2009, he was appointed leader of MERLin at the University of New South Wales (UNSW, Australia). His research focuses on the development of advanced materials for hydrogen technologies and $\mathrm{CO}_{2}$ catalysis.

Zaiping Guo received her PhD in Materials Engineering from the University of Wollongong (Australia) in 2003. She continued her career at the University of Wollongong and received an APD Fellowship and was subsequently appointed as a group leader in 2007. She is currently a Senior Professor in the School of Mechanical, Materials, Mechatronic, and Biomedical Engineering, holding this position since 2014. She received the ARC Queen Elizabeth II

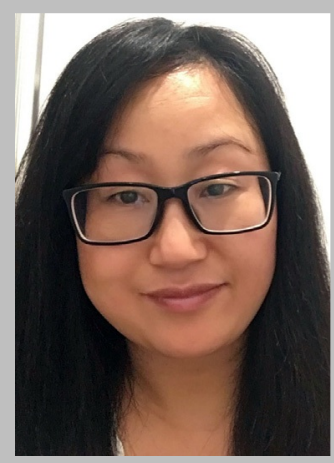
Fellowship in 2010 and the ARC Future Fellowship (FT3) in 2015. Her research focuses on the design and application of nanomaterials for energy storage and conversion, including rechargeable batteries, hydrogen storage, and fuel cells.

\section{Yun Hau Ng received his $\mathrm{PhD}$ from} Osaka University in 2009. After a brief research visit to the Radiation Laboratory at the University of Notre Dame (USA), in 2011 he joined the ARC Centre of Excellence for Functional Nanomaterials at the UNSW with the Australian Postdoctoral Fellowship (APD). He became lecturer (2014) and senior lecturer (2016) in the School of Chemical Engineering, UNSW. He is currently an associate professor in the School of Energy and Environment, City University of Hong Kong. His research is focused on the development of novel photoactive semiconductors for sunlight energy conversion. He received the Honda-Fujishima Prize in 2013 and Distinguished Lectureship Award from the Chemical Society of Japan in 2018.

Da-wei Wang received his $\mathrm{PhD}$ from the Institute of Metal Research, Chinese Academy of Sciences in 2009. He is currently a Senior Lecturer and a Scientia Fellow in School of Chemical Engineering, UNSW. His research ranges from investigating energy materials and their surfaces/interfaces to sustainable electrochemical engineering. He has contributed two book chapters, over 100 journal articles, eight patents and over 20 keynote/invited presenta-

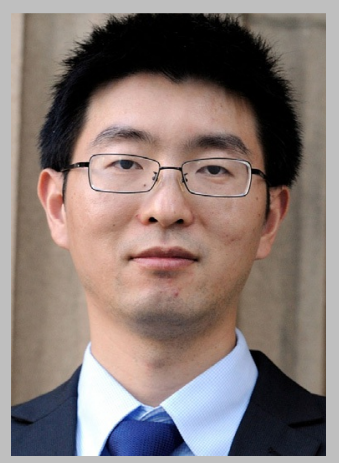
tions. He has won several prestigious awards including the 2013 Scopus Young Researcher Award in Engineering and Technology. 
could, for example, be produced to store energy or supply heat and power on demand for stationary or mobile applications.

Hydrogen is intrinsically safe due to its high volatility and non-toxic nature. Its bad reputation, linked to the explosion of the Hindenburg in 1937, is more related to its broad flammability range in air (4-75\%). To date, the use of hydrogen in the energy sector has mainly focused on mobile applications because of the need for alternative fuels for our cars as oil prices inevitably rise. However, hydrogen will play a broader role in the future. Hydrogen forms the basis of many industrial processes, including the production of synthetic hydrocarbons such as methanol and the production of ammonia through the Haber-Bosch process leading to fertilizers. The ambitious targets worldwide to increase the role of renewables in the energy mix also call for advanced high-capacity energy storage systems to mitigate the intermittency of renewables. In addition to hydrogen, better battery technologies are needed to meet the wide range of our energy needs.

This special issue highlights the potential of a range of materials and novel approaches presented at the Energy Future Conference (organized by UNSW in early 2018) for the production and storage of hydrogen as an energy vector as well as strategies to develop better batteries. The research groups of Huijin Zhao and Roel van de Krol highlight the potential of very exiting approaches for the harvesting of solar energy and water splitting. Umit Demirci and co-workers present a Minire- view on the potential of boron nitride for hydrogen storage. Meanwhile, a novel concept for light-driven hydrogen sorption in material is reported by Yahui Sun and François AgueyZinsou. The groups of Shujiang Ding and Zaiping Guo report on the potential of novel nanostructures for the enhanced performance of lithium ion batteries, and San Jiang and co-workers pre-treated membranes to improve the performance of vanadium redox flow batteries. The potential of a novel method for the fabrication of reduced graphene oxide is presented by Yunhui Lin et al. Also, Yu Hua $\mathrm{Ng}$ and co-workers applied pulsed electrodeposition for enhanced electrochemical water oxidation. Place your cursor over any author name within this Editorial to get direct access to that article.

We hope that you enjoy reading this special issue and that it triggers new ideas to develop future technologies, thus enabling our next transition to clean energy systems.

Keywords: energy storage - future energy technology hydrogen $\cdot$ materials science $\cdot$ water splitting

[1] J. Sušnik, P. van der Zaag, Economic Research-Ekonomska Istraživanja, 2017, 30, 1705-1723.

[2] World Energy Outlook 2017, International Energy Agency, IEA Publications, (https://www.iea.org/Textbase/npsum/weo2017SUM.pdf).

[3] a) M. K. Hubbert, Bull. Assoc. Eng. Geol. 1976, 13, 81; b) M. K. Hubbert, Science 1949, 109, 103.

[4] Q. Lai, T. Wang, Y. Sun, K.-F. Aguey-Zinsou, Adv. Mater. Tech., 2018, 1700298. 